\title{
Impact of the Covid-19 Pandemic on the
} Prolongation of the Management of Myocardial Infarctions Seen Late: A Cross-Sectional Study of 25 Cases Collected in the Cardiology Department of the Aristide Le Dantec Hospital in Dakar (Senegal)

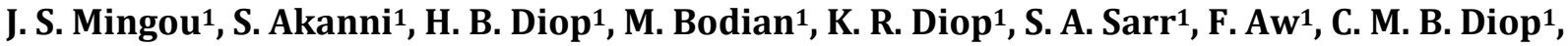

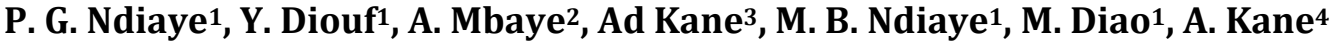 \\ ${ }^{1}$ Cardiology Department, CHU Aristide Le Dantec, Dakar, Senegal \\ ${ }^{2}$ Cardiology Department, Hôpital Général Idrissa Pouye, Dakar, Senegal \\ ${ }^{3}$ Cardiology Department, Saint Louis Regional Hospital, Saint Louis, Senegal \\ ${ }^{4}$ Cardiology Department, Dalal Jamm Hospital, Dakar, Senegal \\ Email: mingoujoseph@gmail.com
}

How to cite this paper: Mingou, J.S., Akanni, S., Diop, H.B., Bodian, M., Diop, K.R., Sarr, S.A., Aw, F., Diop, C.M.B., Ndiaye, P.G., Diouf, Y., Mbaye, A., Kane, A., Ndiaye, M.B., Diao, M. and Kane, A. (2021) Impact of the Covid-19 Pandemic on the Prolongation of the Management of Myocardial Infarctions Seen Late: A Cross-Sectional Study of 25 Cases Collected in the Cardiology Department of the Aristide Le Dantec Hospital in Dakar (Senegal). World Journal of Cardiovascular Diseases, 11, 298-304.

https://doi.org/10.4236/wjcd.2021.116029

Received: April 21, 2021

Accepted: June 25, 2021

Published: June 28, 2021

\begin{abstract}
Background: Timely management determines the prognosis of patients admitted for acute coronary syndrome with persistent ST-segment elevation (STEMI). Coronavirus COVID-19 appeared in China, in Wuhan in December 2019, which has spread at a lightning speed across the planet earth, becoming a pandemic. Senegal, as well as countries around the world, has also been affected by this pandemic, which has had a strong impact on all its sectors of activity, particularly the health system. The objective of this study was to identify and evaluate the factors that increase the time required to treat myocardial infarctions, received late at Hôpital Aristide le Dantec and to assess the impact of the Covid-19 pandemic on these delays. Results: A total of 25 patients were included: 17 patients in pre-pandemic period and 8 patients in pandemic period. The predominance was male with a sex ratio of 2.5. The mean age was 59.20 years. Hypertension was the leading risk factor with a prevalence of $60 \%$ followed by sedentary lifestyle (48\%). Typical chest pain was the most frequent clinical symptom found on admission (80\%) followed by nausea and vomiting (40\%). The first medical contact took place in a hospital in most patients (44\%) and was made by a general practitioner (64\%).
\end{abstract}


Copyright $\odot 2021$ by author(s) and Scientific Research Publishing Inc. This work is licensed under the Creative Commons Attribution International License (CC BY 4.0).

http://creativecommons.org/licenses/by/4.0/
The majority of patients (76\%) were referred to the cardiology department. The personal car was the most frequently used means of transportation for our patients (60\%). The average distance by car between the place of occurrence and the hospital was $22.6 \mathrm{~km}$ with extremes of 3.30 and $36 \mathrm{~km}$. The average travel time from the place of occurrence to the cardiology department was $43 \mathrm{~min} 30 \mathrm{~s}$ with extremes of 11 and $57 \mathrm{~min}$. When comparing the results according to the COVID-19 pandemic, a decrease in the number of incident cases is noted. Before the pandemic, a consultation in multiple units was noted in the majority of cases (41\%) before admission. During COVID-19, the majority of patients (62.5\%) had consulted only one site. The average time from pain to first medical contact was $06 \mathrm{~h} 30 \mathrm{~min}$ before the COVID-19 pandemic and $42 \mathrm{~h} 06$ min during the COVID-19 pandemic. The mean time to electrocardiogram recording was $14 \mathrm{~h} 30$ min before the Covid-19 pandemic and $27 \mathrm{~h} 22$ min during the Covid-19 pandemic. Conclusion: There are significant delays in the management of STEMI patients. They are attributable to both the patients and the system. The main factors of system delay found in our study were the delay in ECG recording, its interpretation, and the organization of transfer via a medical ambulance. The Covid-19 disease has globally aggravated these delays that were already present before the pandemic. Consequent measures must be taken to reduce these delays that determine the vital prognosis of STEMI patients.

\section{Keywords}

Myocardial Infarction, Delays, Covid-19, Senegal

\section{Introduction}

Ischemic heart disease is a major public health concern because of its incidence and morbidity. In 2012, an estimated 7.4 million deaths were attributable to coronary heart disease, representing $12.8 \%$ of global mortality. In 2015 , it was responsible for 15 million deaths or $26.5 \%$ of global mortality. In addition to coronary heart disease, severe acute respiratory syndrome coronavirus 2 (SARS-CoV-2) infection, called Coronavirus Disease 2019 (COVID-19), appeared in China in December 2019. An infectious disease of this magnitude can also lead to management delays in STEMI patients. The literature provides little information on the impact of these emergencies on the pre-hospital and in-hospital logistics of STEMI care, particularly delays related to the patients or the care system [1]. The aim of this series was therefore to identify and evaluate the factors that lengthen delays in the management of STEMI received late at Hôpital Aristide le Dantec and to assess the impact of the Covid-19 pandemic on these delays. The study was conducted over two one-month periods, from March 1, 2019 to March 31, 2019, corresponding to the period before the Covid-19 pandemic, and from August 1, 2020, to August 31, 2020, corresponding to the period during the Covid-19 pandemic. 


\section{Material and Method}

This is a cross-sectional, descriptive, analytical and comparative study over two one-month periods. Patients were recruited over two one-month periods, from March 1, 2019 to March 31, 2019, corresponding to the pre-pandemic Covid-19 period, and from August 1, 2020 to August 31, 2020, corresponding to the per-pandemic Covid-19 period. We included, after informed consent, all patients received for STEMI 12 hours after the onset of pain during the study periods. Not included in the study were:

$\checkmark$ Patients who voluntarily expressed informed refusal.

$\checkmark$ Patients received for ACS without persistent ST-segment elevation (NSTEMI)

$\checkmark$ Patients whose survey forms were not usable

The data were entered using EXCEL software version 2018. Data analysis was performed with SPSS version 20 software. The descriptive study was carried out with the calculation of frequencies and proportions for the qualitative variables and the calculation of averages and the most frequent time slot for the quantitative variables. The analytical study was done with cross-tabulations. To compare frequencies, we used the Pearson Chi-square test or the Fisher two-tailed exact test, depending on the conditions of applicability, with a significance threshold of $\mathrm{p} \leq 0.05$. The Student's t test was used to compare two means with a significance level $\mathrm{p} \leq 0.05$. For the calculation of odds ratios, we had transformed the quantitative variables into qualitative variables with two modalities. For each variable retained in the model, a 95\% confidence interval (CI) had been determined. The significance threshold had been set as classically at $\mathrm{p} \leq 0.05$.

\section{Results}

A total of 25 patients were included: seventeen patients during the pre-Covid-19 pandemic period and eight (8) patients during the Covid-19 pandemic period. The predominance was male with eighteen (18) males (72\%) and seven (7) females $(28 \%)$. The sex ratio $\mathrm{M} / \mathrm{F}$ was 2.5 . The mean age of our patients was 59.20 years with extremes of 40 and 78 years. More than three-quarters of the patients were of low socioeconomic status (75\%). Hypertension was the most frequently noted cardiovascular risk factor (60\%), followed by stress (56\%) and sedentary lifestyle (48\%) (Table 1). Smoking was noted in $36 \%$ of patients and $28 \%$ were diabetic. Typical chest pain was the most frequent functional sign, reported in 20 patients (80\%). Before COVID-19, forty-one percent of patients had visited two centers before admission, thirty-five percent had visited one center, and $24 \%$ had visited 3 centers. During COVID-19, sixty-two point five percent had seen one center prior to admission and $37.5 \%$ had seen two centers. Eleven patients or $44 \%$ had their first medical contact in a hospital, five patients or $20 \%$ in health centers. Four patients (16\%) first consulted private medical centres (practices and clinics). The general practitioner was the first medical contact for 16 patients $(64 \%)$; followed by the nurse $(20 \%)$, cardiologists and DES of cardiology 
Table 1. Comparison of data by time period.

\begin{tabular}{|c|c|c|c|c|}
\hline & \multicolumn{3}{|c|}{ Period } \\
\hline & & \multirow{2}{*}{$\begin{array}{c}\text { Pre-pandemic } \\
\text { Average }\end{array}$} & \multirow{2}{*}{$\begin{array}{c}\text { Per-pandemic } \\
\text { Average }\end{array}$} & \multirow{2}{*}{$\mathrm{P}$} \\
\hline & & & & \\
\hline \multicolumn{2}{|l|}{ Age (years) } & 59 & 59.63 & 0.894 \\
\hline \multicolumn{2}{|c|}{ Distance of occurrence-ALDH (km) } & 24.9 & 17.75 & 0.085 \\
\hline \multicolumn{2}{|c|}{ Average travel time (min) } & 44.76 & 41.13 & 0.462 \\
\hline \multicolumn{2}{|c|}{ Number of structures before admission } & 1.88 & 1.38 & 0.11 \\
\hline \multicolumn{2}{|l|}{$\mathrm{D}-\mathrm{FMC}(\mathrm{min})$} & 392.65 & 2567.5 & 0.007 \\
\hline \multicolumn{2}{|l|}{ FMC-EKG (min) } & 877.94 & 1643.13 & 0.23 \\
\hline \multicolumn{2}{|c|}{ Interpretation time (min) } & 827.35 & 1467.5 & 0.415 \\
\hline \multirow{2}{*}{ Interpretation mode } & Cardiologist on site & $14(82.4 \%)$ & $8(100.0 \%)$ & \multirow{2}{*}{0.296} \\
\hline & By WhatsApp & $3(17.6 \%)$ & $0(0 \%)$ & \\
\hline \multirow{5}{*}{ FMC qualification } & Cardiologist & $1(5.9 \%)$ & $1(12.5 \%)$ & \multirow{5}{*}{0.774} \\
\hline & Nurse & $4(23.5 \%)$ & $1(12.5 \%)$ & \\
\hline & General practitioner & $10(58.8 \%)$ & $6(75.0 \%)$ & \\
\hline & Midwife & $1(5.9 \%)$ & $0(0 \%)$ & \\
\hline & Emergency doctor & $1(5.9 \%)$ & $0(0 \%)$ & \\
\hline
\end{tabular}

ALDH: Aristide Le Dantec Hospital, FMC: First Medical Contact.

(8\%). The average time from the onset of pain to the first medical contact was $1088 \mathrm{~min}$ or 18:36 min, with extremes of $60 \mathrm{~min}$ and 5 days. The most frequent time slot was between $4-8$ am in $44 \%$ of cases. The delay between the pain and the first medical contact was less than 1 hour in $8 \%$ of cases. The analysis according to the study period shows a mean delay of $06 \mathrm{~h} 30 \mathrm{~min}$ before COVID-19 and $42 \mathrm{~h} 06$ min during COVID-19 (Table 1). The mean time from first medical contact to electrocardiogram recording was 18 h 42 min with extremes of $10 \mathrm{~min}$ and 5 days. Subgroup analysis highlights a mean time to ECG recording of 1430 min before Covid-19 and 27 h 22 min during Covid-19 (Table 1). The mean time to ECG interpretation was $1032.20 \mathrm{~min}(17 \mathrm{~h} 12 \mathrm{~min})$ with extremes of $05 \mathrm{~min}$ and $7200 \mathrm{~min}$ ( 5 days). The mean interpretation time before Covid-19 was 827 min (13 h 46 min), the time during Covid-19 was 1467 min (24 h $27 \mathrm{~min}$ ) (Table 1).

\section{Discussion}

Many difficulties were noted during the conduct of the study, including the inability to obtain much more precise information about time delays, and medical care, as most of the information was based on history-taking. Seventeen patients were included during the pre-Covid-19 period and eight patients during Covid-19. This represents a $52 \%$ reduction in the hospital prevalence of STEMI outside the reperfusion delay. These results are in line with those found in Spain [2] with a $40 \%$ decrease in the number of admissions to catheterization rooms 
for STEMI and in the United States between $26 \%$ and $49 \%$ [3]. The reason for this is probably that physical distancing measures, as well as the fear of contracting the virus in hospital units, have led patients to avoid hospital units. In our series, we noted a clear male predominance $(72 \%)$ with a sex ratio of 2.5 . This result corresponds to that found by the INTERHEART Africa study (65\% $80 \%$ ) [4]. On the other hand, in the CORONAFRIC II study the predominance was female [5]. The mean age of our patients was 59.20 years with extremes of 61 and 70 years. Our results are comparable to those of Mboup [6]. In the study by Colin [7], the mean age was 59 years. Marcaggi [8] reported a higher mean age of 68 years in his series. These differences with Western series are in line with the data of coronary disease in developing countries [9] [10] where it is observed that subjects are younger by a decade compared to Western series [8] [11] [12]. Among the main cardiovascular risk factors, arterial hypertension was ranked first with $60 \%$ of cases found. These results are similar to those reported in the literature [5]. The silent nature of hypertension often makes it a largely under-diagnosed and under-treated disease, sometimes revealed by ischemic heart disease. It increases the relative risk of coronary heart disease by 5 times. Sedentary lifestyle was found in $48 \%$ of our patients. These results are higher than those found in the CORONAFRIC II study [5]. Smoking has a strong prothrombotic effect, and smoking cessation is potentially the most effective (in terms of cost) of all secondary prevention measures [13]. It has been established by the INTERHEART study [4] that smoking is the second most important risk factor for myocardial infarction after dyslipidemia. Smoking intoxication was found in $36 \%$ of our patients. The prevalence of diabetes in our study was $28 \%$. Our results are lower than those found in SWEDEN [14]. In our series, 5 out of 7 women were menopausal (25\%). The increased cardiovascular risk after menopause is related to estrogen deficiency [13]. Dyslipidemia was found in $20 \%$ of patients in our study. Typical chest pain was found in $80 \%$ of patients. This is a classic finding reported in several series [15] [16]. Before COVID-19, 41\% of patients had consulted two facilities before admission, $35 \%$ had consulted one facility and $24 \%$ had consulted 3 facilities. During COVID-19 the majority of patients $62.5 \%$ had visited only one centre before admission and $37.5 \%$ had visited two centres. The probable reason for this is the avoidance of hospital care by patients for fear of contracting COVID. The average time between the onset of pain and the first medical contact was 1088 min or 18 hours 36 minutes, with extremes of $60 \mathrm{~min}$ and 5 days. Analysis according to the study period shows a mean delay of 06 h 30 min before COVID-19 and 42 h 06 min (1d 18 h 06 min) during COVID-19. The probable reason for this is that physical distancing measures, as well as the fear of contracting the virus in hospital facilities, also led patients to delay their consultation at hospital centres. The average delay between the first medical contact and the recording of an electrocardiogram (PCM-ECG) was $18 \mathrm{~h} 42 \mathrm{~min}$. This time is significantly shorter than that found by YAMEOGO (8.6 days) [10]. The mean time to ECG recording was $14 \mathrm{~h} 30$ 
min before Covid-19 and 27 h 22 min during Covid-19. This difference could be explained by diagnostic errors due to Covid-19 delaying ECG recording. The recommended delay between PCM and ECG recording should be less than 10 min according to ESC recommendations [17]. Measures should be taken to reduce this first step of the system delay that is more easily improved than the patient delay. The average distance by car between the place of occurrence and the hospital was $22.6 \mathrm{~km}$ with extremes of 3.30 and $36 \mathrm{~km} \cdot \mathrm{s}$. The average travel time between the place of occurrence and the hospital was $43 \mathrm{~min} 30 \mathrm{~s}$ with extremes of 11 and $57 \mathrm{~min}$. An American study found an average travel time of $11 \mathrm{~min}$ and an average distance of $12 \mathrm{~km}$ between the patients' place of residence and the nearest interventional cardiology center [2]. Travel time, even in patients treated on time with reperfusion, has a strong effect on mortality [18]. Efforts by health care systems should focus on reducing pre-hospital and hospital delays. Given the recurrent problems of traffic congestion in the Dakar region this travel time should be taken into account in the organization of pre-hospital care of STEMI patients. Travel time can be used to better estimate the risk of patient mortality as part of a comparative evaluation of the quality of hospital care.

\section{Conclusion}

Early repermeabilization of the occluded artery in STEMI is a priority. Clear guidelines regarding the time from first medical contact to reperfusion therapy have been published. Identifying the factors that increase these delays is an essential step in health systems audit. The Covid-19 pandemic, of unprecedented magnitude, is recognized as a major factor in the disruption of health systems.

\section{Conflicts of Interest}

The authors declare no conflicts of interest regarding the publication of this paper.

\section{References}

[1] Rodríguez-Leor, O., Calid-Álvarez, B., et al. (2020) Impacto de la pandemia de COVID-19 sobre la actividad asistencial en cardiología ntervencionista en España. REC: Interventional Cardiology, 2, 82-89. https://doi.org/10.24875/RECIC.M20000120

[2] Nallamothu, B.K., et al. (2006) Driving Times and Distances to Hospitals with Percutaneous Coronary Intervention in the United States: Implications for Prehospital Triage of Patients with ST-Elevation Myocardial Infarction. Circulation, 113, 1189-1195. https://doi.org/10.1161/CIRCULATIONAHA.105.596346

[3] Garcia, S., Mazen, S., et al. (2020) Reduction in ST-Segment Elevation Cardiac Catheterization Laboratory Activations in the United States during COVID-19 Pandemic. Journal of the American College of Cardiology, 75, 2871-2872. https://doi.org/10.1016/j.jacc.2020.04.011

[4] Yusuf, S., Hawken, S., et al. (2004) Effect of Potentially Modifiable Risk Factors Associated with Myocardial Infarction in 52 Countries (the Interheart Study): Case-Control Study. The Lancet, 364, 937-952. 
https://doi.org/10.1016/S0140-6736(04)17018-9

[5] Ticolat, P., Bertrand, E., et al. (1991) Aspects épidémiologiques de la maladie coronaire chez le noir africain: À propos de 103 cas. Résultats de l'enquête multicentrique CORONAFRIC. Tropical Cardiology, 17, 7-20.

[6] Mboup, M.C., Diao, M., et al. (2014) Les syndromes coronariens aigus à Dakar: Aspects cliniques, thérapeutiques et évolutifs. The Pan African Medical Journal, 19, 126. https://doi.org/10.11604/pamj.2014.19.126.3155

[7] Colin, P., Francois, J., et al. (2001) Angioplastie coronaire à la phase aiguë de l'infarctus du myocarde dans un centre de faible volume. Arch Mal Cour, 94, 651-658.

[8] Marcaggi, X., Bitar, G., et al. (2005) Angioplastie coronaire dans un centre de petit volume. Annales de cardiologie et $d$ angeiologie (Paris), 54, 317-321. https://doi.org/10.1016/j.ancard.2005.05.014

[9] Puymirat, E., Tabassome, S., et al. (2017) Acute Myocardial Infarction Changes in Patient Characteristics, Management, and 6-Month Outcomes over a Period of 20 Years in the FAST-MI Program (French Registry of Acute ST-Elevation or Non-ST-Elevation Myocardial Infarction) 1995 to 2015. Circulation, 136, 1524-4539. https://doi.org/10.1161/CIRCULATIONAHA.117.030798

[10] Yameogo, N.V., Samadoulougou, A., et al. (2012) Délais de prise en charge des syndromes coronariens aigus avec sus-décalage du segment ST à Ouagadougou et facteurs associés à un allongement de ces délais: Étude transversale à propos de 43 cas colligés au CHU-Yalgado Ouédraogo. The Pan African Medical Journal, 13, 90. https://doi.org/10.1161/CIRCULATIONAHA.117.030798

[11] Hanssen, M., Cottin, Y., et al. (2012) French Registry on Acute ST-Elevation and Non ST-Elevation Myocardial Infarction 2010. FAST-MI 2010. Heart, 98, 699-705. https://doi.org/10.1136/heartjnl-2012-301700

[12] Chan, P.S., Patel, M.R., et al. (2011) Appropriateness of Percutaneous Coronary Intervention. JAMA, 306, 53-61. https://doi.org/10.1136/heartjnl-2012-301700

[13] Berdah, J. and Amah, G. (2009) Les facteurs de risque cardiovasculaires concernent aussi les femmes, rôle du gynécologue. Gynécologie Obstétrique \& Fertilité, 37, 186-193. https://doi.org/10.1016/j.gyobfe.2008.12.006

[14] Bonnet, J. (2005) Athérosclérose. Encycl Méd Chir (Elsevier Masson, Paris), Cardiologie; 11-605-A-10, 15 p.

[15] Bagai, A., Dangas, G.D., et al. (2014) Reperfusion Strategies in Acute Coronary Syndromes. Circulation Research, 114, 1918-1928. https://doi.org/10.1016/j.gyobfe.2008.12.006

[16] Danchin, N., Kadriz, Z., et al. (2005) Prise en charge de l'infarctus du myocarde dans les études USIK: Amelioration pronostique et rôle du délai d'admission. Archives des Maladies du Coeur et des Vaisseaux, 98, 1149-1154.

[17] El Boussadani, B., Benajiba, C., et al. (2020) Pandémie COVID-19: Impact sur le systeme cardiovasculaire. Annales de Cardiologie et d' Angéiologie, 69, 107-114. https://doi.org/10.1016/j.ancard.2020.04.001

[18] Di Domenicantonio, R., Cappai, G., et al. (2016) The Tradeoff between Travel Time from Home to Hospital and Door to Balloon Time in Determining Mortality among STEMI Patients Undergoing PCI. PLoS ONE, 11, e0158336.

https://doi.org/10.1371/journal.pone.0158336 